\title{
Specific investments, cognitive resources, and specialized nature of research production in academic institutions: why shared governance matters for performance
}

\author{
Giacomo Degli Antoni ${ }^{1,2}$, Magali Fia ${ }^{3 \star}$ (D) and Lorenzo Sacconi ${ }^{2,4}$ \\ ${ }^{1}$ Department of Law, Politics and International Studies, University of Parma, Parma, Italy, ${ }^{2}$ EconomEtica, Interuniversity \\ Center, University of Milano-Bicocca, Milan, Italy, ${ }^{3}$ Department of Management \& Yunus Social Business Centre, University \\ of Bologna, Bologna, Italy and ${ }^{4}$ Department of Public and Supranational Law, University of Milan, Milan, Italy \\ *Corresponding author. Email: magali.fia@unibo.it
}

(Received 6 September 2020; revised 6 July 2021; accepted 12 July 2021; first published online 2 August 2021)

\begin{abstract}
New institutional economics (NIE) studies institutions and how they emerge, operate, and evolve. They also include organizational arrangements, intended as modes of governing economic transactions. Universities offer an exciting ground for testing the role of different institutional arrangements (governance forms) in coordinating (academic) transactions. In a context of contractual incompleteness where production is characterized by a highly specialized nature and requires the cooperation among co-essential figures, we argue that shared governance models (versus models with more concentrated authority) foster idiosyncratic investments in human capital and promotes performance. From the evolutionary viewpoint, we explain why institutions based on shared governance have developed within universities. The normative question of how universities should be governed is a debated issue in the literature. Since the 1980s, the new public management paradigm provides a theoretical framework that suggests analyzing university like firms. It is based on the firm's archetypical conception as top-down hierarchical organizations and as a descending sequence of principal-agent problems. We advance a different interpretation of the university-firm analogy leveraging on the NIE and its developments. To empirically analyze our hypothesis, we collected original data from Italian universities in 2015. We find that more shared decision-making processes are correlated with better research performance.
\end{abstract}

Keywords: Authority; essential cognitive resources; governance; higher education; institutional economics; shared decisionmaking; specific investments; universities

\section{Introduction}

New institutional economics (NIE) studies institutions and how they emerge, operate, and evolve (Menard and Shirley, 2005). They also include organizational arrangements intended as modes of governing economic transactions (Menard and Shirley, 2005). From Coase (1937), Williamson (1975) to Grossman and Hart (1986) and Hart and Moore (1990), markets and firms (hierarchies) have been widely investigated as alternative governance arrangements. We here leverage governance mode as 'the structure of rights and responsibilities among the parties with a stake in the firm' (Aoki, 2010: 11 ), which facilitate economic transactions (exchanges) and cooperation.

The university domain offers an exciting ground for testing the role of different institutional arrangements (governance forms) in coordinating (academic) transactions. Academic exchanges are characterized by investments in human capital, which are institution- and research program-specific, 
and by co-essential relationship among cognitive assets of different university members. Moreover, the nature of research production requires specialization of decision-relevant knowledge (Dobrajska et al., 2015), i.e. a proper matching between administrators' expertise and the knowledge requested for decisions.

However, so far, the new public management (NPM) paradigm has provided a theoretical framework for analyzing higher education (HE) institutions based on the firm's archetypical conception characterized by top-down hierarchical organizations and a descending sequence of standard principal-agent problems (Braun and Merrien, 1999; De Boer et al., 2007; Kirkpatrick et al., 2017). This approach has marked European public sector reform trends since the 1980s (Pollitt and Bouckaert, 2017). For these institutions, NPM aims to transform external governance (i.e. the relationship between universities and the state) and internal governance (i.e. governing bodies' roles, structures, responsibilities, and decision-making process). This transformation should be done by focusing on accountability and efficiency measures such as performance measurements and pay-for-performance schemes (Ferlie et al., 2008), and introducing a top-down internal chain of command that clarifies responsibilities and speeds up the decision-making process (De Boer et al., 2007). In fact, hierarchical processes and well-defined leadership roles should substitute the collegial decision-making mode to increase effectiveness and responsiveness (Donina et al., 2015). In such a structure, the state indirectly regulates public universities by steering and supervising them and setting output targets and accountability measures linked to government funding (Aghion et al., 2010; Ferlie et al., 2008; Neave, 2012).

Notwithstanding this prevalent stream of literature, many studies pointed out the limitations of using metrics for steering universities and evaluating scientific quality (among others, Mueller, 2017; Osterloh, 2010; Paradeise and Thoenig, 2013). Moreover, whether the (archetypical) governance form of firms suits universities better than a more shared governance model is an issue investigated by Masten $(2006,2019)$ - an author working inside the Williamsonian perspective on institutional economics. He argues that democratic governance guarantees the incentive of individuals who operate within academic institutions to invest where the unilateral allocation of authority cannot be counterbalanced by the mobility of individuals and by the threat of collective actions against self-serving behaviors. ${ }^{1}$ The presence of different theoretical approaches corresponds to the mixed empirical evidence about the relationship between university performance and democracy in the decision-making process (Aghion et al., 2010; Brown, 2001; Cunningham, 2009; Kaplan, 2004; McCormick and Meiners, 1988; Musselin, 2007; Volkwein, 1989; Volkwein et al., 1998).

To go more in-depth in this debate, we offer an interpretation of the relation between the theory of the firm and university that differentiates us from the NPM approach. We also shed new light on the empirical evidence regarding how university governance affects university research performance. We can apply our theoretical approach to private and public universities, as specific investments, cognitive essentialities, and the highly specialized nature of research production characterize both types of institutions. However, because of the lack of data on private universities, we limit our empirical analysis to public universities (see section 'The data source').

We ground our theoretical perspective on university governance in the theory of the firm as a unified governance solution to the problem of contractual incompleteness and opportunism in the presence of specific investments. But, we extend it to account for the issue of coordinating transactions characterized by multiple investments, highly specialized decision-relevant knowledge, and co-essential resources. Following Williamson $(1975,1986)^{2}$ and Aoki (2010), we interpret universities as teams of individuals who undertake significant specific investments in human capital and hold the co-essential cognitive resources to conduct research activities. Moreover, considering the approach by

\footnotetext{
${ }^{1}$ For further incomplete contract considerations within universities and the education domain, see Bernheim and Whinston (1998). For tenure considerations, see, among others, McPherson and Shapiro (1999) and Brown (1997).

${ }^{2}$ Our understanding of Williamson is quite unorthodox (but similar to Blair and Stout, 1999). In fact, we underline that multilateral specific investments imply the opposite of a one-sided hierarchy - based on the primacy of a single-residual control right holder - namely, a constraint on hierarchy through a form of balance of powers and mediation among different interests (i.e. democratic governance forms) (see section 'New-institutional theory and the abuse of authority problem').
} 
Aghion and Tirole (1997), Aghion et al. (2014), and Dobrajska et al. (2015), we highlight the peculiarity of research production in terms of its highly specialized nature and its importance for decisionmaking, especially for the existence of some measure of residual claimancy to part of the surplus of production with the researchers. The allocation of authority affects the incentives to undertake specific investments, the efficiency of the allocation of resources devoted to research production, and the interaction among individuals who hold human cognitive resources, consequently affecting academic activities' performance in terms of research results. In this context, shared governance - versus more autocratic models - becomes a coordination device to sustain the mutually beneficial opportunities of cooperation that may exceed the benefits of unilateral allocation of authority. ${ }^{3}$

To empirically analyze our hypothesis, we use original data collected through a wide-ranging survey conducted among the departments of Italian universities in 2015. Departments are the lifeblood of academic work' (Dearlove, 1997: 92) as they are the places where the research team gathers and joint production is carried out in terms of scientific research. Moreover, serving as a representative unit in the academic government (Moodie and Eustace, 1974), departments are the first building block of university governance. The focus on departments allows to go into the depth of universities' complex internal organizational dynamics, thus being of utmost importance to derive governance considerations. We find that more shared decision-making processes in the departmental level governing units are correlated with better research performance.

Our empirical results do not concern performance measures of teaching and public engagement activities; however, the focus on research performance undermines neither our theoretical nor our empirical analysis. First, the incentives for conducting research are higher for faculty involved in a more shared governance model irrespectively from the university's primary goal (teaching, research, or public engagement). Therefore, our hypothesis holds in the case of multiple-goal universities. Second, our empirical analysis would be undermined only if we could separate faculty members according to the activity pursued: teaching, research, or public engagement activities. But in the empirical context considered (Italy), faculty members which are involved in governance conduct research, teaching, and public engagement activities. Therefore, no substantial distinction emerges among faculty members with this respect. ${ }^{4}$

Our study adds to existing research in three ways. First, we argue that NPM is an approach based on the analogy between universities and firms that does not take in due account the role of specific investments, the uniquely specialized nature of research, and the cooperation among co-essential cognitive resources. Thus, we originally redesigned the university-firm analogy based on an institutional theoretical framework to better understand universities' governance and their evolutions. Second, we empirically test the hypothesis that institutional arrangements that mirror the relationships among essential cognitive resources and protect specific human capital investments perform better than more autocratic models. Third, we contribute to the policy debate with the suggestion that more shared

\footnotetext{
${ }^{3}$ Shared governance as a coordination device is widely explored in the literature on commons (Ostrom, 1990). The production process of research in the university context has important similarities to common pool resources: scientific knowledge is necessarily not excludable to any researchers of the community; and the use of university assets (physical, financial, and organizational) is rival across the university members. Therefore, specific investments undertaken for the development of a research program can be frustrated by opportunistic overuse of such assets by other academic members. Similarly to the depletion of a common pool resource (Hess \& Ostrom, 2006; Potts 2018), one may exercise some authority to gain resources for different priorities (e.g., external programs, visibility, etc.) preventing the achievement of research programs. Besides this similarity, we here exploit the idea that opportunistic behavior and abuse of authority may deplete the university resources by dooming to failure scientific research programs characterized by specific investments and co-essential resources. We study how to avoid such a 'tragedy' of academic commons and sustain specific investments and cooperation among co-essential resources.

${ }^{4}$ Within Italian universities, the figure of permanent researchers had a prevailing (if not exclusive) focus on research activities (Law no. 382 of 11 July 1980). Nevertheless, these researchers have always been in charge for substantial (and paid) teaching activities and responsibilities. Moreover, the role of permanent researchers was terminated by Law no. 240/10 of 30 December 2010. Since then researchers have both teaching and research duties.
} 
governance models are better than more concentrated governance or uncoordinated governance for sustaining research productivity within departments.

The remainder of the paper unfolds as follows. In section 2, we develop our theoretical argument. In section 3, we present our data describing the construction of variables used in the empirical analysis and show the empirical results. In section 4 , we discuss caveats and conclusions.

\section{Corporate governance and performance}

In this section, we provide the theoretical framework to support the idea that shared governance is the most suitable governance solution for organizations characterized by co-essentiality of resources and specific investments in highly specialized activities, as universities are. We also discuss the costs and benefits of shared decision-making versus centralized authority. We develop our argument by considering the key elements of the NIE and its developments (section 'The new-institutional theory, formal versus substantial authority, and Aoki's view') in relation to the academic context (section 'The academic context'); we then define our hypotheses (section 'The theoretical hypotheses').

\section{The new-institutional theory, formal versus substantial authority, and Aoki's view}

\section{New-institutional theory and the abuse of authority problem}

The NIE understands firms as means to govern economic transactions through hierarchy versus market coordination (contracts) (Coase, 1937). ${ }^{5}$ Within this approach, incompleteness of contracts (i.e. future contingencies cannot be agreed upon ex-ante because of bounded rationality) when specific investments are important (Williamson, 1975, 1986) opens the way for opportunistic behavior that can affect the distribution of the value produced among the parties. In this perspective, after the contract, the party with more bargaining power can exploit the unilateral or mutual dependence that investments create to its benefit at the detriment of the other party, i.e. the so-called hold-up problem (Williamson, 1986). Therefore, market transactions, which entail promises that cannot be secured by incomplete contracts, will fail in terms of efficiency loss. The NIE's normative solution suggests a mechanism based on the allocation of formal authority (Grossman and Hart, 1986; Hansmann, 1988; 1996; Hart, 1995; Hart and Moore, 1990; Williamson, 1975; 1986). Authority represents power over discretional decisions - left ex-ante unspecified in an incomplete contract because of unforeseen contingencies, but commanding obedience ex-post - that affect the investments' value. ${ }^{6}$ Authority should be assigned to the subject who makes the most important specific investment to preserve her incentives to invest as it avoids the hold-up problem; at the same time, the other party will under-invest in the transaction (Grossman and Hart, 1986; Hart and Moore, 1990).

However, when specific investments are multilateral, the unilateral allocation of authority does not prevent ex-post abuse. The party who holds the residual control right can abuse her authority by expropriating the joint surplus accruing from non-controlling stakeholders' multilateral specific

\footnotetext{
${ }^{5}$ NIE, a term first introduced by Williamson (1975), goes beyond the border of transaction cost economics to deal with institutional and organizational matters (among which is included the description of firms as governance structures). For an historical overview on the concept, see Furubotn and Richter (2008).

${ }^{6}$ For Alchian and Demsetz (1972), the main problem in a team production is that 'the marginal products of cooperative team members are not so directly and separably (i.e. cheaply) observable' (Alchian and Demsetz, 1972: 780). Corporation is a 'contractual organizations of inputs' (nexus of contracts) which emerges as an efficient monitoring device in team production assuming that team members are effort-averse and shirk whenever they can. First, centralized decision-making (in the hand of a specialized-monitor of the teams' members) lowers the costs of detecting marginal productivity through specialization. Second, the residual claimant status of the monitor incentivizes s/he not to shirk as monitor. However, in Alchian and Demsetz view there is no accepted authority (a là Arrow), since contracts are seen as complete even if characterized by asymmetric information and costly monitoring. Therefore, their approach does not consider the costs of continuously bargaining around issues not specified in the (incomplete) contracts. But, ignoring the possibility of unforeseen contingencies also forgets the risk of abuse of the principal's discretionary power. We here account for the role and the risks of formal authority and agency costs.
} 
investments and from their cooperative participation in team production (Sacconi, 1999, 2000, 2011). Therefore, the incentive to invest for the non-controlling parties can substantially decrease thus, in the long run, causing an overall surplus reduction. Nevertheless, at least in the short run, the party in the position of authority may be incentivized to abuse since she gains a private advantage from the appropriation of the joint surplus that repays her for the overall surplus reduction. It shows an unfairness problem in the exercise of the residual control right. In fact, the unilateral allocation of authority aims to protect the controlling party's investment and not allow the expropriation of the other participants' share of the surplus.

The problem of abuse of authority is not solved when we consider Hansmann's analysis of the firm's alternative ownership structures (Hansmann, 1988, 1996). Hansmann compares different governance forms by accounting for their contracting costs (because of information asymmetry, incompleteness, and market power) and governance costs (related to the exercise of control - monitoring/ agency or collective decision-making costs - and to risk-bearing). All the solutions he considers are unilateral (or mono-stakeholder). The efficient ownership form is the one that, taking each stakeholder's contract costs as given, minimize 'the sum of both market contracting for those patrons who are not owners, and the cost of ownership for the class of patrons [e.g., capital investors, employees, suppliers, customers, other beneficiaries etc.] who are assigned ownership' (Hansmann, 1988: 273). Hansmann assumes that the contract costs of the non-controlling stakeholders and of the ownership structure selected are independent. But, for example, if the authority is given to the capital investor, employees' contract costs may increase because of what we call 'abuse of authority'. On the one hand, investors' governance costs are lower than employees' ones because investors have homogeneous interests (profit maximizations) and vice versa (Hansmann, 1988). On the other hand, the contract incompleteness leaves open the potential abuse of authority of the owners (investors) to the detriments of employee, thus increasing employees' contract costs and challenging the identified efficiency solutions.

In this context, one would enquire whether some mutual balance principle or participation in sharing decision-rights across different stakeholders could improve the costs' trade-off. In fact, without falling into the opposite mono-stakeholder solution of employee-owned firms, such principles may reduce the contracting costs raised for the risks associated with the unilateral allocation of ownership to investors. Only a commitment to respect all the legitimate interests and rights of all the noncontrolling stakeholders can counterbalance the risk that the party in authority position may abuse its discretionary power. ${ }^{7}$ Governance and accountability measures such as participation and information rights in the decision-making process may guarantee the respect of this commitment (Fia and Sacconi, 2019; Sacconi, 2006, 2011). Shared governance in the university context is a significant, historical, and well-documented example of an institutional mechanism preventing the abuse of authority.

Centralized versus decentralized authority in the presence of specialized decision-relevant knowledge Besides the abuse of authority, unilateral decisions may result in poor choices simply because of limited or partial information of the central authority, and hence being harmful to the overall level of value created by the organization. The costs and benefits of centralized versus decentralized authority have been widely discussed in the literature within the principal-agent framework (among others, Aghion et al., 2014; Aghion and Tirole, 1997; Dobrajska et al., 2015). The two relevant subjects are identified as the principal, who has the formal control, and the agent, who has not formal control,

\footnotetext{
${ }^{7}$ In practice, we do observe different models in which the concentration of authority is counterbalanced by different rights. For example, the co-determination model of German large corporations (Gelter, 2009) in which workers' representative sit in the supervisory boards. Further examples are the Japanese model of managerial capitalism (Aoki, 2010), American tradition of corporate law that understands the firm as a 'mediating hierarchy' (Blair and Stout, 1999; Stout 2012), Benefit Corporations (Hiller, 2013), and European social cooperatives (Sacchetti, 2015). We can also think to CSR self-regulations and policies which are soft-law governance mechanisms that balance unilateral allocation with responsibilities toward non-controlling stakeholders (Sacconi, 2006, 2011).
} 
but de facto carries out tasks in the organization and hence has the relevant knowledge. Specifically, the main distinction is between formal authority, i.e. the legitimate power to choose from a given action set where the subordinate accepts that choice as the premise for its execution, and substantial authority, i.e. the knowledge on the decision variables (and their consequences) in the action set which are controlled by the party having formal authority (Aghion and Tirole, 1997; Aghion et al., 2014, 2021). An interesting question consequently is whether it could be rational from the principal view point to decentralize formal authority, and hence associating formal authority to substantial authority by delegating it to the more informed agent. In particular, the problem of authority delegation occurs when the principal prefers one project (considered as the 'organizational objective'), whereas the agent prefers another project (considered the 'Agent's private objective'). The probability that the agent's choice corresponds to the principal's preferred project is the degree of congruence of the two parties' interests, and it is assumed to be less than one. By undertaking a costly investment, the principal can acquire the capability to recognize the best (for her) project and to reject different proposal. Thus, the principal's decision about authority delegation deals with the costs of becoming informed about the best project (for her) and with the degree of interest congruence. In the presence of an intense conflict of interests (the congruence degree is low), the benefit of becoming informed - and not delegating authority - may outweigh its cost. On the contrary, when the degree of congruence is high it may be rational to delegate authority.

Within organizations in which the highly specialized knowledge necessary to take decisions is possessed by the agent who actually delivers and performs the task and cannot be transferred efficiently (at lower costs and efforts) it would be irrational for the principal to decide for centralized authority (Aghion et al., 2014; Aghion and Tirole, 1997; Dobrajska et al., 2015). ${ }^{8}$ Typically, this occurs in firms closer to the technological frontier (Aghion et al., 2014, 2021) where centralized authority without the necessary information may result in a mistaken assessment of the optimal project. Namely, the best use of the unique information possessed by the specialized individuals can be made by delegating decisions to the agent or actively cooperating with her.

\section{Aoki's view}

Aoki provides a further understanding of corporate governance's role, departing from the idea that a governance model serves primarily to control opportunistic behavior but to sustain the mutually beneficial opportunities from cooperation (Aoki, 2010). ${ }^{9}$

In Aoki's view, firms are team production between investors' financial resources and managers' and workers' cognitive resources. ${ }^{10}$ Specifically, managers understand the firm's position in the world (i.e. the overall environment), workers have a micro-perspective on firms' operations (i.e., the local environment), and investors are the physical owner of capital goods. He defines corporate governance as the rules of the game which regulate interactions among the team's members (Aoki, 2010). According to the various characteristics of the relationship between workers, managers, and investors, Aoki identifies different governance models. The entrepreneurial ownership (intended as the residual

\footnotetext{
${ }^{8}$ Empirical studies show that some circumstances favors the emergence of decentralization, such as the level of competition in the market (Bloom et al., 2010) and the level of generalized trust in the region where the headquarter of the firm is located (Bloom et al., 2012).

${ }^{9}$ See also Hodgson (2004) on the necessity for not deriving management considerations based only on Williamson's concept of opportunism.

'A manager inspired by Williamson's analysis would concentrate principally on the installation of monitoring structures to minimize opportunistic behavior. [...]. In some circumstances monitoring would be ineffective, even with access to all information and in the absence of opportunism. [...] Sometimes principals cannot monitor agents even when information on behavior is costless, because they do not have necessary knowledge about production process or outcomes. [...] Minkler [1993] argues that this situation of dispersed knowledge requires a more participatory governance structure for the firm' (Hodgson, 2004: 411-412).

${ }^{10}$ The notion of cognitive resources used by Aoki refers 'not only mental activities (perceiving, imaging, guessing, theorizing, deciding, etc.) but also physical ones (operating machines, uttering speech, typing an e-mail, etc.)’ (Aoki, 2010: 29).
} 
control right to one party, the owner) and the hierarchical control (Grossman and Hart, 1986; Hart and Moore, 1990) are only particular cases. Within firms having a team dimension a là Alchian and Demsetz (1972) and involving multiple investments and competencies that are mutually essential, the managers need the workers' cooperation to use the physical assets productively; simultaneously, the latter requires the managers' strategies to use their cognitive assets (Aoki, 2010). These firms need a corporate governance model that can sustain and foster information-sharing and cooperation for joint production. ${ }^{11}$ This occurs when the authority (i.e. the residual control right) is shared between managers and workers. Managers and workers achieve cooperation through co-decisionmaking between the holders of essential cognitive assets, and the owners of physical assets take the role of supervision. Cooperation among workers and managers is particularly relevant when knowledge creation is of utmost importance, while the physical resources remain in the background for organizational considerations. For example, this situation occurs in knowledge-intensive organizations such as law firms, consulting companies (Aoki, 2010).

To summarize, the governance model may entail different degrees of decision-making sharing that provide checks and balances to sustain multiple specific investments and essential cognitive resources of different participants in the companies.

\section{The academic context}

According to the theoretical framework outlined above, we interpret universities as a mode of governing academic transactions characterized by specific investments, a highly specialized nature of research production, also associated with members' residual claimancy on university output, and co-essential resources.

\section{Specific investments}

We understand the specificity of the investment undertaken by faculty and researchers as an investment in human capital regarding a scientific research program that restricts alternatives and reduces mobility toward other programs. Consider, for example, the case of a research program where faculty and researchers should gain program-specific human capital (e.g., specific language, basic assumptions, and heuristics) that is specific also to the team working on that program. In this perspective, the researchers' human and cognitive resources lose their value if the program stops. In principle, mobility toward a similar program is possible as epistemic communities and networks may extend beyond a specific university's boundaries. However, moving an entire team from a university to another can be costly. A single researcher can also incur high individual costs associated with moving to a different team (even with similar research trajectories). A decentralized and shared decisionmaking (versus centralized authority) provides the counterbalances between the involved agents, e.g., central administrators, the rector, or deans at the department level, and the responsible for alternative or concurrent research programs or scientific teams. This governance arrangement allows to increase efficiency by reducing the risk of abuse of authority associated with specific investments and misbehaviors characterizing joint production.

\section{Peculiarities of research production: the highly specialized nature of knowledge and residual claimancy}

Besides abuse of authority, it is also worth noting the peculiarities of research production in terms of the highly specialized nature of the output produced. Even more than in firms closer to the technological frontier (Aghion et al., 2014), universities operate at the boundary of knowledge to develop new investigations and evidences. A natural interpretation of substantial authority within universities deals with the specialized decisions of each discipline (e.g. the selection of teaching and research projects

\footnotetext{
${ }^{11}$ This occurs when the contributions of managers and workers are not separable as in the case of Alchian and Demsetz (1972) and neither party can benefit from the control of financial resources without the cooperation of the other.
} 
and the personnel to implement them). No academician from a different field or university administrator usually claim to be able of gaining the specialized knowledge necessary to overcome the judgment of the specialized academic bodies in these decisions.

Moreover, a significant share of the surplus produced in a research program cannot be extracted from the individual researcher. This aspect of the research production endows faculty members with a (partial) residual claimant status with respect to research excellence (Brown, 1997, 2001; McCormick and Meiners, 1988). Therefore, faculty involved in the different research programs have both incentives and the expertise to make effective decisions concerning investments in the programs.

Although there are costs connected with shared decisions due to the problems associated with team production: horizon problems, i.e. short-termism in taking decisions; incentive problems - as individuals bear only a fraction of the cost; and inalienability of cash flows rights (McCormick and Meiners, 1988), the expertise of faculty members is crucial in the university context as they hold knowledge which is relevant for high-quality decision. The lack of the requisite information needed to optimally decide research output for all specialized areas will thus result in poorer/suboptimal decisions. Moreover, the research production process needs cooperative production among specialized researchers, which add a third element to consider.

\section{Coessentiality and organizational structure}

Adapting Aoki's framework to the university context, the internal organization is represented by faculty members and administrators, while the public authorities represent the external finance (donors represent external finance within a private university). The co-essentiality within universities is evident in the team dimension of research programs. Faculty members' role seems to be fundamental because they are holders of knowledge necessary to evaluate decisions on curriculum, conduct research programs, and design new research trajectories, teaching programs, and general faculty decisions (see also Brown, 2001). In this perspective, co-essentiality is evident among human capital of teams' members. The technical-administrative staff has complementary resources to conduct research activities. Technical-administrative staff provides various services and holds the knowledge of the organization's rules and practices to support research activities (from managing founding requests to managing promotions activities, organizing conferences, etc.). Administrators have the overall competencies necessary to address strategic planning, budget, facilities planning, and political action. ${ }^{12}$ The combination of human resources within research teams working on a research program generates interdependencies and joint productivity, affecting the bargaining over the surplus division and, therefore, their incentives to undertake their human cognition investments. In fact, neither party can gain stronger bargaining power from controlling resources. For example, administrators managing research funds, hiring, and facilities cannot go too far without faculty members' cooperation. Similarly, a single coalition of faculty members cannot benefit from controlling resources without administrators and other faculty members' cooperation.

To summarize, shared governance may cause high costs when it is extremely shared or when it ends up in uncoordinated governance models. Such costs are connected with indecisiveness, slower decision-making, and gridlock (Masten, 2006). However, a shared governance arrangement (versus centralization) allows to increase efficiency by reducing the typical risks of joint production in research programs associated with specific investments (abuse of authority as in the hold-up problem) and with suboptimal organizational design (as when decisions are taken in a uniformed manner due to the lack of expertise). It also reflects the characteristic of research production in terms of inseparability from the output and cognition characteristics, thus preserving the incentives to undertake investments and supporting cooperation among the organization members. Shared powers reflect the enlarged commitment (responsibilities) of the party endowed with authority, who runs the university not for her interests rather for sustaining joint productivities made of investments and co-essential resources.

\footnotetext{
${ }^{12}$ Note that administrators (e.g., president, provost) in the US universities often have an academic background. Although in European universities they mostly serve also as faculty members.
} 


\section{The theoretical hypotheses}

Ferris and McKee (2005) view departments as academic teams a là Alchian and Demsetz (1972). The distribution of resources for research activities decided by a single stakeholder category is subject to opportunism problems and to the risk of uninformed decisions that may affect the mutually advantageous potential of cooperation. For example, the department director may unilaterally decide to allocate resources without considering specific investments already undertaken and results already pursued thanks to these investments, which may need further funds. This decision may be the result of the lack of correct information on the advantages obtainable by these projects or of the pursuit of different goals, such as increasing visibility through short-term initiatives. This implies a damage for researchers who do not see their investments and cooperative effort to conduct research activities protected against opportunistic or uninformed decisions. We do not maintain that universities should finance research programs without an evaluation of their performance. However, the incentives to start fruitful research projects are lower if the department chair's decision is at risk of an unfair behavior due to the abuse of authority or of poor decisions just because of a lack of information. A shared governance model can sustain these incentives by reducing these risks.

Based on the framework outlined above, we now synthesize our view by a deductive argument based on three hypotheses ${ }^{13}$ :

Hypothesis 1. Specific investments by faculty involving specialized and co-essential human resources allow to get a higher level of performance.

Hypothesis 2. Specific investments of academics are always subject to the risk of abuse of authority due to contract (and governance) incompleteness and of uninformed/suboptimal decisions.

Hypothesis 3. In the presence of multilateral specific investments, the incentives to undertake specific investments are greater when governance is more shared between the representative of teams (responsible for the various research programs) rather than when it is more concentrated.

Given the three hypotheses formulated above, in the academic context, we can expect to observe higher performance when we observe that decision-making power is distributed among different organization members rather than when it is concentrated in the hand of a single agent.

Figure 1 describes the connections among governance model, specific investments and co-essentiality of resources, and performance with a temporal illustration. The reference to a sequence of time slots is useful to shows the mechanism of exchange and retroaction typical of scientific knowledge production. ${ }^{14}$ In $t_{0}$, shared governance sustains the organizational architecture characterized by co-essential resources and individuals undertaking specific investments. In $t_{1}$, we expect to see a better performance (e.g., concerning publications and research projects) than in a case in which governance is concentrated (Figure 1, the upper part - but we can replicate the reasoning for the subsequent time slots).

Two counter-arguments to our explanation concern the reverse causality problem and the possible competitive advantage that leads universities offering shared governance to attract more productive researchers. With respect to the reverse causality problem, members having a high performance in $t_{1}$ may seek to impose a shared governance model in $t_{2}$ (Figure 1 - dashed arrow). However, this event is not a falsifier of our hypothesis as our theoretical argument incorporates this possibility: if a set of individuals having co-essential human resources, incentivized by a shared governance model, undertake specific investments in $t_{0}$, they will tend in $t_{1}$ to maintain or strengthen (if they have the freedom to decide) a shared governance architecture that protects these investments (Figure 1 - dotted arrow). This situation

\footnotetext{
${ }^{13}$ We take a hypothetical-deductive approach (cf. Nagel, 1961) in which we verify that our hypotheses are not falsified in the data (Popper, 1963).

${ }^{14}$ This figure shows the evolutionary path of shared governance depicted by applying NIE to describing the functioning over time of institutional mechanism based on shared governance. See Hodgson and Stoelhors (2014) for a description of similarities and differences between evolutionary economics and NIE.
} 


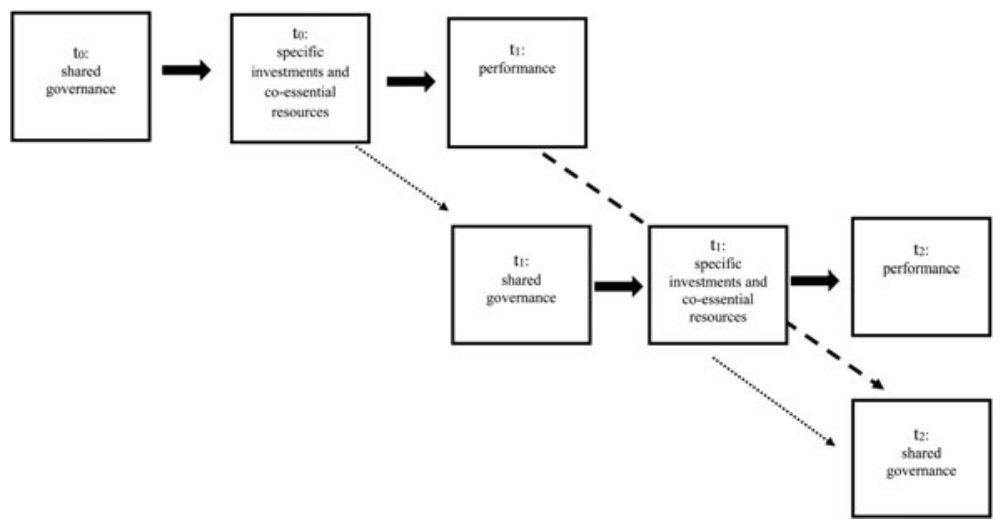

Figure 1. The virtuous pattern between shared governance,-specific investments, and essential resources' performance.

promotes the performance in $t_{2}$ and maintains or even strengthens a shared governance model. As far as the competitive advantage issue is concerned, one may think that more productive researchers are attracted by universities characterized by greater shared governance, either because of their enhanced bargaining power or because of preferences for such contexts. However, also this event is not a falsifier of our hypothesis as it does not contradict that shared governance - versus more autocratic models results in greater productivity on the part of the same set of researchers, ceteris paribus. ${ }^{15}$

Therefore, if we observe an association between shared governance and higher performance with respect to a concentrated governance model, our hypothetical deductive explanation is legitimate to run as follows: given our theoretical hypotheses that (1) high performance of scientific research programs necessarily requires specific investments, and that (2) shared governance is a necessary requirement for the undertaking and maintenance of specific investment into scientific research programs, (3) when we observe higher performance when governance model is more shared, then (4) we infer that shared governance is contributing in determining high performance.

Our theory's potential falsifier is represented by the following empirical case: when better performance is associated with more concentrated governance than more shared governance models. This is what our theory explicitly negates since highly concentrated governance entails the risk of abuse of authority and induces a decline in specific investments. The theory will be corroborated if we do not observe that concentrated governance is correlated with higher performance, with the additional (milder) support that when productivity is higher, typically governance is shared.

\section{Empirical analysis}

In our empirical analysis, we investigate the relationship between different models of governance and proxies of performance.

\section{The unit of analysis}

The analysis focuses on the 911 departments of the 83 Italian universities. ${ }^{16}$ They comprise not less than 35 members, including professors, temporary researchers, and lifelong researchers (minimum 40 members for major universities). ${ }^{17}$

\footnotetext{
${ }^{15} \mathrm{We}$ thank an anonymous referee for suggesting this interpretation.

${ }^{16}$ The small number of Italian universities (65 public universities and 18 private universities) led us to avoid performing a multivariate analysis on this sample.

${ }^{17}$ In Italian universities, full professors and associate professors are tenure positions. Researcher is permanent position which did not include mandatory teaching duties (which now is being eliminated). Temporary researchers correspond to
} 


\section{The data source}

Our database includes governance categories, indices of performance at the departmental level, and control variables. Because no recent measure of the locus of authority exists, we surveyed all the 911 departments of the 83 Italian universities. ${ }^{18}$ We conducted the investigation between June and November 2015 through a computer-assisted web interviewing with 835 questionnaires addressed to public universities' department chairs ${ }^{19}$ and yielding a response rate of $38.7 \%{ }^{20}$ We divide the survey questions into five sections; we here focus on the section on the decision-making process, which captures the allocation of the decision authority.

As proxies of performance, we use two measures: an index elaborated by the Italian Agency for the Evaluation of Universities and Research Institutes (ANVUR) based on publications; and an index elaborated by the Italian Social Investments Research Facility (CENSIS) based on the success in receiving funding for research projects.

We collected and elaborated control variables from various sources: ANVUR and CINECA (a consortium of universities operating to support the Italian Ministry of Education, University and Research: MIUR) databases provide university characteristics and other selected survey items; the Italian National Institute of Statistics (ISTAT), Italian Ministry of Economy and Finance, and the Ministry of the Interior provide context variables (see Table A1 for details).

\section{Description of variables}

\section{Governance categories}

Italian university departments have their governing unit (the department council); a deliberative body that addresses teaching and research functions and approves formal departmental decisions. The council members are the department chair, full professors, associate professors, researchers, temporary researchers, technical-administrative staff representatives, and student representatives. An executive committee assists the department chair, and the presidents of degree courses represent another essential category in particular for teaching activities at the departmental level.

The construction of the governance categories that identify the locus of decision authority was an in-depth process of aggregating the department chairs' responses. The survey asked them to report the degree of influence (from 'none' to 'a great deal' - in a Likert scale of 5) for each figure involved in the decision-making process: department chair, executive department committee, presidents of degree courses, full professors, associate professors, researcher, temporary researcher, technical-administrative staff representatives, and student representatives. Our categories do not merely replicate formal authority (even if it affects them); instead, they capture the allocation of substantial (de facto) authority in the decision-making process that is not always ascribable to formal voting rights. Understanding governance arrangements based on informed respondents' perceptions of power allocation beyond the formal rules is a consolidated methodology in university governance studies (Kaplan, 2004;

the two now possible types of contract (since Law no. 240 of 2010): 'type A' and 'type B', with different lengths and career possibilities but similar duties.

${ }^{18}$ The survey on Italian universities was conducted with the scientific and financial support of EconomEtica (an interuniversity research center based in Milano Bicocca University), the Department of Sociology and Social Research at the University Milano Bicocca, and the POLIS department of the University of Piemonte Orientale, and it was sponsored by the Conference of Italian Universities' Rectors (CRUI).

${ }^{19} \mathrm{We}$ also sent 76 surveys to the department chairs of private universities; the response rate was $27.6 \%$ (21 answers). The low number of answers in absolute terms prevents us from conducting significant analysis.

${ }^{20}$ The relatively low response rate may bias our empirical results. This would be the case if departments characterized with a more shared (more concentrated) governance model are more likely to fill in the survey when they have a higher performance (a lower performance). However, to our knowledge there is no reason for that occurrence. Conversely, we argue that, once starting to fill in the survey, department chairs belonging to departments with higher performance should be more willing to result as the 'leader' of the department, with a more concentrated governance model. Vice-versa, the department chairs of departments with a lower performance may tend to declare themselves as less influential than they actually are. Both these effects are better explained in the next section and are not in favor of our theory. 
Masten, 2006). Even though bias related to a 'demand effect' on respondents' answers may exist, we argue that it would not provide empirical support to our theoretical arguments. Department chairs belonging to high-performance departments should be more willing to reveal themselves as the 'leader' with concentrated power. Vice versa, the department chairs who do not have high performance may tend to declare themselves as less influential than they actually are, revealing a more 'shared' governance. Both these effects tend to contradict the empirical evidence that supports our theory.

At the end of the aggregation process, we identified six categories at the departmental level: Leader, Balanced hierarchy, Representative, Multiple balances, Unstructured hierarchy, and Flat. See Table A3 for details concerning the aggregation process to elaborate the governance categories. The governance categories capture the degree of shared governance at the departmental level, from an extreme in which the authority is concentrated on the department chair to a situation in which it is widely spread among different stakeholder categories.

Leader shows when the department chair is more influential than other stakeholder categories. It represents the de facto concentration of authority in the departmental leader's hand, suggesting a lack of protection for human capital specific investments.

Balanced hierarchy shows a governance structure in which underlying joint-producing teams are represented in faculty members' decision-making process. Specifically, the full professors' influence as team representatives provides a balance to the department chair's decision authority. This category captures a less concentrated allocation of power in the decision-making process with respect to the Leader category outlined above. Moreover, it suggests a governance pattern in which the subjects with a substantial investment in human capital at stake (full professors) have a powerful role as team representatives.

Representative identifies a situation in which the department chair, together with directors of degree courses (heads of study of bachelor, master, and Ph.D. programs) or the executive committee (a group of full professors elected to represent each scientific area belonging to the department), are the most influential individuals. This category captures an allocation of authority in which the department chair's authority is balanced by stakeholders who, because of their institutional role, represent various teams.

Multiple balances shows a governance structure in which balances are even higher with respect to Balance hierarchy and Representative. Here, at least two categories among full professors, executive committee, or director of degree courses provide a balance to the department chair's decision authority. In this situation, the representation of the different interests at stake can protect from the risk of abuse of authority.

Unstructured hierarchy represents a situation in which the authority is allocated without following common representation mechanisms. This situation occurs when a category that rarely acts as a team representative (researchers, technical-administrative staff, and student) has a relevant power position or when the team representatives (full professors, executive committee, or presidents of degree courses) have more power than the department chair. Therefore, interests are represented in an unstructured manner, and decisions may be made based on temporarily influential individuals rather than on representation mechanisms.

Flat index groups two situations that capture different participation by including influence thresholds of various stakeholders. First, department chairs with full professors, executive committee, heads of degree courses, and associate professors have more than 'enough' influence. Second, department chairs with full professors, executive committee, presidents of degree courses, and at least one other category have the same influence level. It shows a more decentralized governance pattern but where no clear distribution of authority exists. This flat hierarchy may show that teams do not have substantial authority for counterbalancing decisions that may negatively affect teams' investments. Responsibilities and accountabilities are unclear. Therefore, this allocation of authority may not be effective at incentivizing specific investments.

Table 1 provides summary statistics for our governance index across universities and shows that most departments fall within the leader and balanced hierarchy category. Note that our categories 
Table 1. Decision-making authority at the departmental level (number of departments and percentage)

\begin{tabular}{lcccccc}
\hline Leader & $\begin{array}{c}\text { Balanced } \\
\text { hierarchy }\end{array}$ & Representative & $\begin{array}{c}\text { Multiple } \\
\text { balances }\end{array}$ & $\begin{array}{c}\text { Unstructured } \\
\text { hierarchy }\end{array}$ & Flat & Non-classified \\
\hline $66(20.43 \%)$ & $78(24.15 \%)$ & $34(10.53 \%)$ & $55(17.03 \%)$ & $46(14.24 \%)$ & $12(3.72 \%)$ & $32(9.91 \%)$ \\
\hline
\end{tabular}

do not cover all the combinations of department chairs' answers concerning decision authority allocation. Some departments (9.91\%) result as non-classified because departments' chairs' replies do not match any category.

\section{Performance indices}

We use a performance indicator related to research activities. The indicator (Publications) concerns the publication activity. It is based on the research products published by members of the departments of public Italian universities in 2016. It considers the heterogeneity in the composition of departments in terms of scientific areas within the departments. In fact, its value is determined on the basis of each department positioning in the class of all departments with the same disciplinary composition. Moreover, it is not a purely quantitative measure. The evaluations of research products are either based on the peer review method ${ }^{21}$ or on a bibliometric analysis (for articles in bibliometric areas indexed in the Web of Science and Scopus databases) (Table A1).

\section{Control variables}

We control for institutional characteristics: the heterogeneity of departments (the number of different disciplines within each department, the distinction between hard and social science departments, dummy variables capturing the preeminent scientific area within the department); the dimension of the university the departments belong to; the context in which universities are located (variables at the territorial level such as income per capita, population, and population density in the area and proxies linked to aspects concerning immaterial factors capable of favoring cooperation and development in the area, such as participation in the referendum and the recycling rate); the geographical location of departments, distinguishing between departments located in northern, central, and southern Italy and the islands (Tables A1 and A2).

\section{Results}

We now present the results from multiple regression analysis, in which we regress the performance variable on dummy variables for each of the governance categories and control variables (Table 2).

After categorizing each department using the governance categories, we incorporate them in the model as qualitative independent variables (dummies), taking leader as the base group. The dependent variable is the performance index at the departmental level: publications. Note that we drop the unclassified departments from our analysis. ${ }^{22}$ To control for a potential multicollinearity issue, we computed variance inflation factors (VIFs). All the VIFs estimated (in relation to single variables and the mean VIF) for both the regressions considered in the analysis are less than $10 .^{23}$ We then exclude that multicollinearity is a problem in our analysis (Mela and Kopalle, 2002).

Equation (1) considers a dummy among control variables taking the value of 1 if the department is a hard science department. Equation (2) includes single dummies capturing the preeminent scientific

\footnotetext{
${ }^{21}$ The judgment of quality concerning is based on the criteria of originality, methodological rigor and certified or potential impact. The analysis based on these criteria converges in a synthetic judgment on the research product, articulated on five levels: Excellent; High; Fair; Acceptable; Limited.

${ }^{22}$ As clarified in section 'Description of variables', some departments (9.91\%) result as non-classified, because replies given by departments' chair do not match any governance category.

${ }^{23}$ The mean VIF is equal to 2.13 with respect to equation (1) and 2.09 with respect to equation (2) (Table 2).
} 
Table 2. Ordinary-least squares (OLS) results at the departmental level

\begin{tabular}{|c|c|c|}
\hline & (1) (OLS) & (2) (OLS) \\
\hline Equation & \multicolumn{2}{|c|}{ Dependent variable: Publications } \\
\hline Balanced hierarchy & $14.450^{\star \star}(6.300)$ & $13.517^{\star \star}(6.386)$ \\
\hline Representative & $19.837^{\star \star}(7.972)$ & $23.679^{\star \star \star}(8.080)$ \\
\hline Multiple balances & $17.986^{\star \star}(7.307)$ & $20.267^{\star \star \star}(7.462)$ \\
\hline Unstructured hierarchy & $2.476(7.338)$ & $6.909(7.521)$ \\
\hline Flat & $-13.530(13.201)$ & $-7.041(13.286)$ \\
\hline Plu_dip & $-1.728(1.355)$ & $-1.933(1.478)$ \\
\hline Faculty_14 & $-0.000(0.003)$ & $0.002(0.004)$ \\
\hline Income_pc & $0.001(0.001)$ & $0.001(0.001)$ \\
\hline Referendum & $0.232(0.281)$ & $0.193(0.288)$ \\
\hline Recycling_rate & $0.282(0.258)$ & $0.251(0.266)$ \\
\hline Pop_province & $-0.000(0.000)$ & $0.000(0.000)$ \\
\hline Density & $0.002(0.001)$ & $0.002^{\star}(0.001)$ \\
\hline North & $30.506^{\star \star \star}(9.802)$ & $29.498^{\star \star \star}(9.952)$ \\
\hline Central & $28.675^{\star \star \star}(9.443)$ & $29.773^{\star \star \star}(9.567)$ \\
\hline Hard_science_department & $-0.184(4.650)$ & \\
\hline Physical sciences & & $27.522(17.587)$ \\
\hline Chemical sciences & & $10.820(11.277)$ \\
\hline Earth sciences & & $-13.477(15.686)$ \\
\hline Biological sciences & & $17.380(13.013)$ \\
\hline Medical sciences & & $2.022(10.667)$ \\
\hline Agricultural and veterinary sciences & & $-5.605(11.596)$ \\
\hline Civil engineering and architecture & & $28.296^{\star \star}(11.789)$ \\
\hline Industrial and information engineering & & $1.378(10.815)$ \\
\hline $\begin{array}{l}\text { Sciences of antiquity, philological-literary, and historical-artistic } \\
\text { sciences }\end{array}$ & & $6.090(10.478)$ \\
\hline Historical, philosophical, pedagogical, and psychological sciences & & $-0.627(11.108)$ \\
\hline Legal sciences & & $13.230(11.441)$ \\
\hline Economic and statistical sciences & & $10.877(11.119)$ \\
\hline Political and social sciences & & $-0.014(11.959)$ \\
\hline Constant & $-1.691(17.129)$ & $-12.923(18.614)$ \\
\hline $\begin{array}{l}t \text { test on the equality of the coefficients balanced hierarchy and } \\
\text { representative }\end{array}$ & $-5.387(7.636)$ & $-10.162(7.785)$ \\
\hline $\begin{array}{l}t \text { test on the equality of the coefficients balanced hierarchy and } \\
\text { multiple balances }\end{array}$ & $-3.535(6.882)$ & $-6.750(7.087)$ \\
\hline $\begin{array}{l}t \text { test on the equality of the coefficients balanced hierarchy and } \\
\text { unstructured hierarchy }\end{array}$ & $11.975^{\star}(7.038)$ & $6.609(7.262)$ \\
\hline$t$ test on the equality of the coefficients balanced hierarchy and flat & $27.981^{\star \star}(13.074)$ & $20.558(13.231)$ \\
\hline
\end{tabular}


Table 2. (Continued.)

\begin{tabular}{|c|c|c|}
\hline \multirow[t]{2}{*}{ Equation } & (1) (OLS) & (2) (OLS) \\
\hline & \multicolumn{2}{|c|}{ Dependent variable: Publications } \\
\hline $\begin{array}{l}t \text { test on the equality of the coefficients representative and multiple } \\
\text { balances }\end{array}$ & $1.851(8.395)$ & $3.412(8.419)$ \\
\hline $\begin{array}{l}t \text { test on the equality of the coefficients representative and } \\
\text { unstructured hierarchy }\end{array}$ & $17.362^{*}(8.595)$ & $16.770^{*}(8.602)$ \\
\hline$t$ test on the equality of the coefficients representative and flat & $33.367^{\star \star}(13.925)$ & $30.720^{\star *}(13.949)$ \\
\hline $\begin{array}{l}t \text { test on the equality of the coefficients multiple balances and } \\
\text { unstructured hierarchy }\end{array}$ & $15.510^{\star \star}(7.778)$ & $13.359^{*}(7.297)$ \\
\hline$t$ test on the equality of the coefficients multiple balances and flat & $31.5160^{\star \star}(13.300)$ & $27.308^{\star \star}(13.401)$ \\
\hline $\begin{array}{l}t \text { test on the equality of the coefficients unstructured hierarchy and } \\
\text { flat }\end{array}$ & $16.006(13.509)$ & $13.949(13.583)$ \\
\hline Observations & 264 & 264 \\
\hline $\operatorname{Adj}-R^{2}$ & 0.249 & 0.259 \\
\hline
\end{tabular}

Standard errors in parentheses. ${ }^{\star \star \star} p<0.01,{ }^{\star \star} p<0.05,{ }^{\star} p<0.1$.

areas within the department; the residual category concerns mathematical and computer sciences departments. ${ }^{24}$ The significant positive values assumed by the coefficients of balanced hierarchy, representative, and multiple balances in both the estimates presented in Table 2 show that departments with a more democratic pattern of decision authority perform better in terms of the publications index than departments whose governance category is leader. Or, vice versa, leader performs worse than the case in which the department chair cooperates with at least one other stakeholder category among full professors, executive committee, or heads of degree courses. Moreover, in both the estimates, the $t$ tests on the equality of the coefficients of unstructured hierarchy and flat and the two categories representative and multiple balances reveal that departments have a worse performance when interests are represented in an unstructured manner or decisions may be made based on temporarily influential individuals (unstructured hierarchy), or when the authority of the department chair is not clearly recognized within the department (flat). ${ }^{25}$ In other words, governance models in which the authority of the department chair is counterbalanced by the full professors and/or by the head of degree courses and/or the executive committee lead to better performance in terms of publications compared to models in which the department chair has greater authority than all other stakeholder categories or in which more categories of stakeholders assume greater authority in the decisionmaking process, or in which the authority of the department chair is not fully recognized within the department. These results are also in line with the classical study in human relations (among others Lewin and Lippitt, 1938) who showed that democratic leadership performs better than authoritarian leadership and much better than 'laissez-faire'. Regarding the control variable, a positive effect emerges in two regional dummy variables that identify departments in northern and central Italy: we find that departments in the north and central Italy perform better than those in the other regions.

To conclude, by including interaction terms, we checked for possible different effects of our governance model categories with respect to: (i) the type of department - by distinguishing between hard

\footnotetext{
${ }^{24}$ Since, for the lack of more detailed information, 66 departments have been classified by considering the scientific areas in the department and its name, two robustness checks in which the more ambiguous departments in terms of classifications have been dropped or identified by a further dummy have been performed. Results concerning the governance indices are in line with those presented in Table 2, excepts from the unstructured hierarchy which performs better than the governance models captured by the flat index when the 66 departments are dropped from the sample.

${ }^{25}$ When considering equation (1), a better performance emerges also when considering the balanced hierarchy with respect to the unstructured hierarchy and flat indices.
} 
science department and social science department; and (ii) the number of scientific areas within the departments. Since the interaction terms are not statistically significant, we did not include them in the estimates.

\section{Discussion}

Universities represent an interesting ground for testing hypotheses of institutional economics and developments. The governance structure of current university systems evolved in the directions of major or minor shared governance. We can explain this by two factors.

Human capital investments of faculty members in research teams represent significant specific investments within academia. In a context of contractual incompleteness and specific investments, the theory prescribes that governance arrangements allocating authority are more efficient than markets in governing transaction (Williamson, 1975, 1986). However, the unilateral allocation of authority does not prevent the ex-post opportunism. The party who holds discretional-decision power can abuse her authority by expropriating the joint surplus accruing from non-controlling stakeholders' specific investments and from their cooperative participation in team production.

Besides abuses, the highly specialized nature of research production requires specialized decisionrelevant knowledge and benefits from the cooperation among the university's co-essential figures. With this respect, the theory suggests that to reduce the risk of making ineffective decision because of the lack of competencies in the presence of subordinates' decision-relevant knowledge, decentralization may perform better than centralized authority (Aghion et al., 2014; Dobrajska et al., 2015). It also prescribes that co-essential resources need a cooperative mode of governance rather than an autocratic one (Aoki, 2010).

We argue that, if applied to the university context, the previous theoretical considerations can support shared governance mechanisms within academia. We then suggest that a governance structure that considers the characteristics of the academic transaction and the relationships among cognitive resources is of primary importance for research performance. Moreover, we provide additional evidence on the relationship between governance and performance within universities. According to Williamson, a seminal Coase' lesson is 'the importance of studying real word institutions' to improve economic analysis of institutions (Williamson, 2015: 221). In this vein, our paper allows us to derive governance considerations that enrich the current institutional economic debate.

Sharing powers and taking part in the decision process allow to counterbalance any attempt of the stakeholders having a position of authority to abuse their position or to reduce the risk to take uninformed decisions. This has positive effects on human resource investment and cooperation and, finally, on scientific productivity. However, limitations exist where governance is extremely shared. In these cases, costs related to slow-decision-making or lacks of coordination may exceed the benefit of shared governance.

The results point toward a significant positive correlation between departmental performance in terms of research products and a governance model, where the decision authority is shared among the department chair and the holders of essential resources for conducting research activities. Vice versa, the more the decision authority is concentrated in the hand of the department chair, the worse the performance.

As a result of research activities, publications are a typical example of team production among the holders of different human resources. Moreover, publications are the results of specific investments and co-essential resources that require protection and support to be productive. The theoretical framework we adopted conjectures that specific investments, the highly specialized nature of research production and positive cooperation among co-essential human resources (i) allow getting a higher level of performance and (ii) are promoted by shared governance models, which allow tackling the problem of contract (and governance) incompleteness. Our empirical results exclude that most hierarchical department governance goes hand in hand with higher performance (what would have falsified our theory). Moreover, they are consistent with the hypothesis that a shared governance structure in 
which team members' representatives influence the decision-making process (counterbalancing the department chair's authority) supports a higher performance level at the departmental level. We do agree that causality is hard to prove without longitudinal data on governance change at time 0 and performance at time 1. But, the hypothetical-deductive argument provided in section 'The theoretical hypotheses' and summarized above gives us reasons to maintain that our results corroborate the view that shared governance positively affects performance by favoring specific investments, informed decisions, and cooperation among co-essential resources.

We now come to the second result of our empirical analysis. The balancing of authority must have certain characteristics to improve performance. Performance is not positively affected by governance structures in which: (i) many (more than three) categories of stakeholders have the same authority as the chair or; (ii) the authority of the department chair is not clearly recognized within the department. This suggests the need for a governance structure in which the distribution of influence is coherent with the specific investments and co-essential resources. That is, granting significant influence to many categories in the decision-making process may have detrimental effects. In fact, the decentralized power without a clear distribution of authority may generate the perception among the different stakeholder categories that they have no power to influence the decision-making process.

Therefore, our results seem relevant in the NIE debate on hierarchies' role by opening up the black box on the role of authority. We here conceive authority as a bundle of rights and duties (information rights, participation rights, etc.) which can be distributed among distinct class of stakeholders. Different checks and balances shape governance form from the top-down unilateral mode to shared governance until unstructured hierarchy.

Moreover, we contribute to the debate surrounding university governance and HE sector reforms. Specifically, our evidence challenges the NPM reform trend in European HE, which aims at transforming universities' internal governance that mirrors archetypical corporate-like structures and uses metrics as a key steering device (Aghion et al., 2010; Ferlie et al., 2008). The NPM narrative emphasizes metrics as the accountability device that legitimates a top-down internal chain of command. As a caveat, we share much of the criticism on the limitations of using metrics for evaluating scholars' value (see section 1). But, we argue that, even if one accepts to assess performance through publications' metrics, what follows is not a top-down governance mechanism as suggested by NPM. In fact, the virtuous pattern (see section 'The theoretical hypotheses') shows that higher productivity is connected with higher selfcontrol of the department by the academicians who invest their human resources in team production.

Future research could shed light on the different mechanisms driving the effect of governance structures on performance measures, not only in terms of research results, but also concerning teaching activities.

\section{References}

Aghion, P. and J. Tirole (1997), 'Formal and Real Authority in Organizations', Journal of Political Economy, 105(1): 1-29. Aghion, P., N. Bloom and J. Van Reenen (2014), 'Incomplete Contracts and the Internal Organization of Firms', The Journal of Law, Economics, \& Organization, 30(1): i37-i63.

Aghion, P., M. Dewatripont, C. M. Hoxby, A. Mas-Colell and A. Sapir (2010), 'The Governance and Performance of Universities: Evidence From Europe and the US', Economic Policy, 25(61): 7-59.

Alchian, A. and H. Demsetz (1972), 'Production, Information Costs, and Economic Organization', The American Economic Review, 62(5): 777-795.

Aoki, M. (2010), Corporations in Evolving Diversity: Cognition, Governance, and Institutional Rules, Oxford: Oxford University Press.

Bernheim, B. D. and M. D. Whinston (1998), 'Incomplete Contracts and Strategic Ambiguity', American Economic Review, 88 (4): 902-932.

Blair, M. M. and L. A. Stout (1999), 'A Team Production Theory of Corporate Law', Virginia Law Review, 85(2): $247-328$.

Bloom, N., R. Sadun and J. Van Reenen (2010), 'Does Product Market Competition Lead Firms to Decentralize?', American Economic Review, 100(2): 434-438.

Bloom, N., R. Sadun and J. Van Reenen (2012), 'The Organization of Firms Across Countries', The Quarterly Journal of Economics, 127(4): 1663-1705. 
Braun, D. and Merrien, F. X. (eds.). (1999). Towards a New Model of Governance for Universities?: A Comparative View, London/Philadelphia: J. Kingsley.

Brown, W. O. (1997), 'University Governance and Academic Tenure: A Property Rights Explanation', Journal of Institutional and Theoretical Economics, 153(3): 441-461.

Brown, W. O. (2001), 'Faculty Participation in University Governance and the Effects on University Performance', Journal of Economic Behavior \& Organization, 44(2): 129-143.

Coase, R. H. (1937), 'The Nature of the Firm', Economica, 4(16): 386-405.

Cunningham, B. M. (2009), 'Faculty: Thy Administrator's Keeper? Some Evidence', Economics of Education Review, 28(4): 444-453.

Dearlove, J. (1997), 'The Academic Labour Process: From Collegiality and Professionalism to Managerialism and Proletarianisation?', Higher Education Review, 30(1): 56.

de Boer, H., J. Enders and Schimank U. (2007), 'On the Way Towards New Public Management? The Governance of University Systems in England, the Netherlands, Austria, and Germany’, in D. Jansen (ed), New Forms of Governance in Research Organizations, Dordrecht: Springer, pp. 137-152.

Dobrajska, M., S. Billinger and S. Karim (2015), 'Delegation within Hierarchies: How Information Processing and Knowledge Characteristics Influence the Allocation of Formal and Real Decision Authority', Organization Science, 26(3): 687-704.

Donina, D., M. Meoli and S. Paleari (2015), 'Higher Education Reform in Italy: Tightening Regulation Instead of Steering at a Distance', Higher Education Policy, 28(2): 215-234.

Ferlie, E., C. Musselin and G. Andresani (2008), 'The Steering of Higher Education Systems: A Public Management Perspective', Higher Education, 56(3): 325-348.

Ferris, J. S. and M. McKee (2005), 'Matching Candidates with Academic Teams: A Case for Academic Tenure', International Review of Law and Economics, 25(2): 290-310.

Fia, M. and L. Sacconi (2019), 'Justice and Corporate Governance: New Insights from Rawlsian Social Contract and Sen's Capabilities Approach', Journal of Business Ethics, 160(4): 937-960.

Furubotn, E. G. and R. Richter (2008), 'The New Institutional Economics - A Different Approach to Economic Analysis', Economic Affairs, 28(3): 15-23.

Gelter, M. (2009), 'The Dark Side of Shareholder Influence: Managerial Autonomy and Stakeholder. Orientation in Comparative Corporate Governance', Harvard International Law Journal, 50(1): 129-134.

Grossman, S. J. and O. D. Hart (1986), 'The Costs and Benefits of Ownership - A Theory of Vertical and Lateral Integration', Journal of Political Economy, 94(4): 691-719.

Hansmann, H. (1988), 'Ownership of the Firm', Journal of Law, Economics, and Organization, 4(2): 267-304.

Hansmann, H. (1996). The Ownership of Enterprise, Cambridge MA: Harvard University Press.

Hart, O. (1995), Firms, Contract and Financial Structure, Oxford: Clarendon Press.

Hart, O. and J. Moore (1990), 'Property-rights and the Nature of the Firm', Journal of Political Economy, 98(6): 1119-1158.

Hess, C. and E. Ostrom (eds) (2006), Understanding Knowledge as a Commons, Cheltenham: Edward Elgar.

Hiller, J. S. (2013), 'The Benefit Corporation and Corporate Social Responsibility', Journal of Business Ethics, 118(2): $287-301$.

Hodgson, G. M. (2004), 'Opportunism is Not the Only Reason Why Firms Exist: Why an Explanatory Emphasis on Opportunism may Mislead Management Strategy', Industrial and Corporate Change, 13(2): 401-418.

Hodgson, G. M. and J. W. Stoelhorst (2014), 'Introduction to the Special Issue on the Future of Institutional and Evolutionary Economics', Journal of Institutional Economics, 10(4): 513.

Kaplan, G. E. (2004), 'Do Governance Structures Matter?', New Directions for Higher Education, 127: 23-34.

Kirkpatrick, I., A. Altanlar and G. Veronesi (2017), 'Corporatisation and the Emergence of (Under-Managered) Managed Organisations: The Case of English Public Hospitals', Organization Studies, 38(12): 1687-1708.

Lewin, K. and R. Lippitt (1938), 'An Experimental Approach to the Study of Autocracy and Democracy: A Preliminary note', Sociometry, 1(3/4): 292-300.

Masten, S. E. (2006), 'Authority and Commitment: Why Universities, Like Legislatures, are Not Organized as Firms', Journal of Economics and Management Strategy, 15(3): 649-684.

Masten, S. E. (2019), 'The Senseless Monstrosity in our Path: Academic Bargains and the Rise of the American University', in N. P. McCluskey and T. J. Zywicki (eds.), Unprofitable Schooling: Examining the Causes of, and Fixes for, America's Broken Ivory Tower, Washington, DC: Cato Institute, pp. 173-193.

McCormick, R. E. and R. E. Meiners (1988), 'University Governance - A Property-Rights perspective', Journal of Law \& Economics, 31(2): 423-442.

McPherson, M. S. and M. O. Schapiro (1999), 'Tenure Issues in Higher Education', Journal of Economic Perspectives, 13(1): 85-98.

Mela, C. F. and P. K. Kopalle (2002), 'The Impact of Collinearity on Regression Analysis: The Asymmetric Effect of Negative and Positive Correlations', Applied Economics, 34(6): 667-677.

Ménard, C. and Shirley, M. M. (eds.) (2005), Handbook of New Institutional Economics (Vol. 9), Dordrecht: Springer.

Moodie, G. and R. Eustace (1974), Power and Authority in British Universities, Montreal: McGill-Queen's University Press.

Mueller J. Z. (2017), The Tyranny of Metrics, Princeton: Princeton University Press. 
Musselin, C. (2007), 'Are Universities Specific Organisations? In Towards a Multiversity?', in G. Krücken, A. Kosmützky, and M. Torka (eds), Universities Between Global Trends and National Traditions, Bielefeld: Transcript, pp. 63-84.

Nagel, E. (1961), The Structure of Science, New York: Harcourt.

Neave, G. (2012), The Evaluative State, Institutional Autonomy and Re-Engineering Higher Education in Western Europe: The Prince and his Pleasure, United Kingdom: Palgrave Macmillan.

Osterloh, M. (2010), 'Governance by Numbers. Does It Really Work in Research?', Analyse \& Kritik, 32(2): $267-283$.

Ostrom, E. (1990) Governing the Commons. The Evolution on Institutions for Collective Action. Political Economy of Institutions and Decisions Series, Cambridge UK/New York USA: Cambridge University Press.

Paradeise, C. and J. C. Thoenig (2013), 'Academic Institutions in Search of Quality: Local Orders and Global Standards', Organization Studies, 34(2): 189-218.

Pollitt, C. and G. Bouckaert (2017), Public Management Reform: A Comparative Analysis: A Comparative Analysis (4th edition.), Oxford, UK: Oxford University Press.

Popper, K. (1963). Conjectures and Refutations: The Growth of Scientific Knowledge, London: Routledge.

Potts, J. (2018), 'Governing the Innovation Commons', Journal of Institutional Economics, 14(6): 1025-1047.

Sacchetti, S. (2015), 'Inclusive and Exclusive Social Preferences: A Deweyan Framework to Explain Governance Heterogeneity', Journal of Business Ethics, 126(3): 473-485.

Sacconi, L. (1999), 'Codes of Ethics as Contractarian Constraints on the Abuse of Authority within Hierarchies: A Perspective from the Theory of the Firm', Journal of Business Ethics, 21(2-3): 189-202.

Sacconi, L. (2000), The Social Contract of the Firm Economics, Ethics and Organization, Berlin: Springer.

Sacconi, L. (2006), 'A Social Contract Account for CSR as an Extended Model of Corporate Governance (I): Rational Bargaining and Justification', Journal of Business Ethics, 68(3): 259-281.

Sacconi L. (2011), 'A Rawlsian View of CSR and the Game Theory of its Implementation (Part I): The Multi-Stakeholder Model of Corporate Governance', in L. Sacconi, M Blair, R. E. Freeman and A. Vercelli (eds), Corporate Social Responsibility and Corporate Governance, London: Palgrave Macmillan, pp. 157-193.

Stout, L. (2012), The Shareholder Value Myth: How Putting Shareholders First harms Investors, Corporations, and the Public, Oakland: Berrett-Koehler Publishers.

Volkwein, J. F. (1989), 'Changes in Quality among Public Universities', Journal of Higher Education, 60(2): 136-151.

Volkwein, J. F., S. M. Malik and M. Napierski-Prancl (1998), 'Administrative Satisfaction and the Regulatory Climate at Public Universities', Research in Higher Education, 39(1): 43-63.

Williamson, O. E. (1975), Market and Hierarchies, New York, NY: The Free Press.

Williamson, O. E. (1986), The Economic Institutions of Capitalism, New York, NY: The Free Press.

Williamson, O. E. (2015), 'Ronald Harry Coase: Institutional Economist and Institution Builder', Journal of Institutional Economics, 11(2): 221. 


\section{Appendix A}

Note. Concerning the control variables at the territorial level, we opted for data at the municipality level when available. Otherwise, we considered the province in which the university is located. MIUR (Ministry of University and Education); ANVUR (the Italian Agency for the Evaluation of Universities and Research Institutes); CINECA (Consortium of Universities operating in support of the MIUR), and other selected survey items for university characteristics; ISTAT (the Italian National Institute of Statistics). ${ }^{26}$

Table A1. Variable descriptions and data sources

\begin{tabular}{|c|c|c|}
\hline Variable & Description & Source \\
\hline Publications & $\begin{array}{l}\text { 'The ISPD (the name of indicator used for the departmental } \\
\text { performance) value assigned to a particular department will } \\
\text { be determined on the basis of its positioning in the class of } \\
\text { all departments with the same disciplinary composition (i.e. } \\
\text { the same structure in terms of SSD (academic fields and } \\
\text { discipline) of the members) that can be composed of } \\
\text { permuting the members present in those SSDs in Italian } \\
\text { public institutions on } 1 \text { January } 2017 \text { (virtual department } 1 \text { ). } \\
\text { ISPD will therefore be obtained only by direct comparison } \\
\text { between the departments with the same disciplinary } \\
\text { composition, and this comparison will be made in terms of } \\
\text { the degree of success in the last VQR (Research Quality } \\
\text { Assessment) note' (from the Methodological note on the } \\
\text { calculation of the indicator - https://www.miur.gov.it/ } \\
\text { dipartimenti-di-eccellenza). 'The VQR is divided into } 16 \\
\text { Research areas; for each area, ANVUR has set up a group of } \\
\text { evaluation experts with the task of evaluating the products } \\
\text { of the research. The number of products to be proposed for } \\
\text { evaluation by research staff varies according to their role } \\
\text { and the type of institution, as indicated in the VQR Call for } \\
\text { Proposals. The evaluations are based on the peer review } \\
\text { method and, for articles in bibliometric areas indexed in the } \\
\text { Web of Science and Scopus databases, on bibliometric } \\
\text { analysis. [...] The judgment of quality concerning is based } \\
\text { on the criteria of originality, methodological rigor and } \\
\text { certified or potential impact. The analysis based on these } \\
\text { criteria converges in a synthetic judgment on the research } \\
\text { product, articulated on five levels: Excellent; High; Fair; } \\
\text { Acceptable; Limited' (from http://www.anvur.it/attivita/vqr/ } \\
\text { vqr-2011-2014/) }\end{array}$ & ANVUR ranking 2016 \\
\hline
\end{tabular}


Physical sciences; Chemical sciences; Earth sciences; Biological related to hard science

sciences; Medical sciences; Agricultural and veterinary sciences

Dummy identifying the preeminent scientific area within the department

ANVUR 2013, Authors' elaboration

Civil engineering and architecture; Industrial and information

engineering; Sciences of antiquity, philological-literary and

historical-artistic sciences; Historical, philosophical, pedagogical

and psychological sciences; Legal sciences; Economic and

statistical sciences; Political and social sciences

Number of scientific areas (CUN - Italian national university

ANVUR 2013, Authors' elaboration

\section{Faculty_14} council - classification) within the department

\begin{tabular}{|c|c|c|}
\hline Num_dip & Number of departments - University level & CINECA 2016 \\
\hline Income_pc & Income per capita - 2009 - municipality level & $\begin{array}{l}\text { Calculated using income tax data } \\
\text { from the Italian Ministry of } \\
\text { Economy and Finance }\end{array}$ \\
\hline Referendum & Participation in the referendum - 2009 - province level & Ministry of the Interior \\
\hline Pop_province & Resident population as of 31.12 .2009 - municipality level & ISTAT \\
\hline Density & $\begin{array}{l}\text { Population density (inhabitants } / \mathrm{km}^{2} \text { ) in } 2009 \text { - municipality } \\
\text { level }\end{array}$ & ISTAT \\
\hline North & Dummy variable: university location - North of Italy & ISTAT CLASSIFICATION \\
\hline Central & Dummy variable: university location - Center of Italy & ISTAT CLASSIFICATION \\
\hline
\end{tabular}


Table A2. Descriptive statistics (concerning classified departments)

\begin{tabular}{|c|c|c|c|c|}
\hline Variable & Mean & Std. Dev. & Min & Max \\
\hline Leader & 0.227 & 0.419 & 0 & 1 \\
\hline Balanced hierarchy & 0.268 & 0.444 & 0 & 1 \\
\hline Representative & 0.117 & 0.322 & 0 & 1 \\
\hline Multiple balances & 0.189 & 0.392 & 0 & 1 \\
\hline Anarchy & 0.158 & 0.365 & 0 & 1 \\
\hline Flat & 0.041 & 0.199 & 0 & 1 \\
\hline Publications & 51.511 & 41.193 & 0 & 100 \\
\hline Hard_science_department & 0.546 & 0.499 & 0 & 1 \\
\hline Plu_dip & 3.378 & 1.818 & 1 & 11 \\
\hline Faculty_14 & $1,224.241$ & 842.547 & 37 & 3,555 \\
\hline Value_added & $16,520.8$ & $3,305.99$ & 10,409 & 22,360 \\
\hline
\end{tabular}

Table A3. Independent variable definition: governance categories at the departmental level

\begin{tabular}{|c|c|}
\hline Variable & Description \\
\hline Leader & $\begin{array}{l}\text { The department chair (having more than 'enough' influence) is more influential than any } \\
\text { other stakeholder category (having no more than 'enough' influence) }\end{array}$ \\
\hline Balanced hierarchy & $\begin{array}{l}\text { The department chair and full professors are endowed with decision authority (having more } \\
\text { than 'enough' influence) as long as the remaining members do not have more than } \\
\text { 'enough' influence }\end{array}$ \\
\hline Representative & $\begin{array}{l}\text { The department chair together with one of the other representatives, that is, the executive } \\
\text { committee or presidents of degree courses, has strong influence (having more than } \\
\text { 'enough' influence) in the decision-making process as long as the remaining members do } \\
\text { not have more than 'enough' influence }\end{array}$ \\
\hline Multiple balances & $\begin{array}{l}\text { The department chair together with at least two categories among full professors, executive } \\
\text { committee, or presidents of degree courses have more than 'enough' influence in the } \\
\text { decision-making process, as long as the remaining members do not have more than } \\
\text { 'enough' influence }\end{array}$ \\
\hline $\begin{array}{l}\text { Unstructured } \\
\text { hierarchy }\end{array}$ & $\begin{array}{l}\text { The index groups two possible cases. First, at least one stakeholder among researchers, } \\
\text { temporary researchers, technical-administrative staff representatives, and student } \\
\text { representatives has more than 'enough' influence, irrespective of the degree of influence } \\
\text { of the other categories. Second, full professors, executive committee, or presidents of } \\
\text { degree courses have more than 'enough' influence in the decision-making process, as } \\
\text { long as the department chair does not have more than 'enough' influence }\end{array}$ \\
\hline Flat & $\begin{array}{l}\text { The index groups two possible cases that capture different forms of participation by } \\
\text { including influence thresholds of various stakeholders. First, department chairs with hill } \\
\text { professors, executive committee, presidents of degree courses, and associate professors } \\
\text { have more than 'enough' influence. Second, department chairs with full professors, } \\
\text { executive committee, presidents of degree courses, and at least one other category have } \\
\text { the same level of influence }\end{array}$ \\
\hline
\end{tabular}

We derive six governance categories from an aggregation process drawn from the question made to the department chairs: 'Beyond the provisions under the law, please characterize your impression of the level of influence of the categories listed below in the decision-making process in the department council: department chair, department executive committee, presidents of degree courses, full professors, associate professors, researcher, temporary researcher, technical-administrative staff representatives, student representatives'. The possible responses for each category were 'a great deal', 'much', 'enough', 'little', and 'none'.

Cite this article: Degli Antoni G, Fia M, Sacconi L (2022). Specific investments, cognitive resources, and specialized nature of research production in academic institutions: why shared governance matters for performance. Journal of Institutional Economics 18, 655-676. https://doi.org/10.1017/S1744137421000655 